\title{
Deletion of pic results in decreased virulence for a clinical isolate of Shigella flexneri 2a from China
}

\author{
Junqi Zhang ${ }^{1,2}$, Lisheng Qian', Yang Wu ${ }^{2}$, Xia Cai ${ }^{2}$, Xueping Li ${ }^{1}$, Xunjia Cheng ${ }^{1 *}$ and Di Qu ${ }^{2 *}$
}

\begin{abstract}
Background: Shigella is a major pathogen responsible for bacillary dysentery, a severe form of shigellosis. Severity of the disease depends on the virulence of the infecting strain. Shigella pathogenicity is a multi-gene phenomenon, involving the participation of genes on an unstable large virulence plasmid and chromosomal pathogenicity islands.

Results: A multiplex PCR (mPCR) assay was developed to detect $S$. flexneri 2a from rural regions of Zhengding (Hebei Province, China). We isolated and tested 86 strains using our mPCR assay, which targeted the ipaH, ial and set1B genes. A clinical strain of S. flexneri 2a 51 (SF51) containing ipaH and ial, but lacking set1B was found. The virulence of this strain was found to be markedly decreased. Further testing showed that the SF51 strain lacked pic. To investigate the role of pic in S. flexneri 2a infections, a pic knockout mutant (SF301- $\triangle$ pic) and two complementation strains, SF301- $\triangle$ pic/pPic and SF51/pPic, were created. Differences in virulence for SF51, SF301- $\triangle$ pic, SF301- $\triangle$ pic/pPic, SF51/pPic and S. flexneri 2a 301 (SF301) were compared. Compared with SF301, both SF51 and SF301- $\triangle$ pic exhibited lower levels of Hela cell invasion and resulted in reduced keratoconjunctivitis, with low levels of tissue damage seen in murine eye sections. The virulence of SF301- $\triangle$ pic and SF51 was partially recovered in vitro and in vivo through the addition of a complementary pic gene.
\end{abstract}

Conclusions: The pic gene appears to be involved in an increase in pathogenicity of S. flexneri 2a. This gene assists with bacterial invasion into host cells and alters inflammatory reactions.

Keywords: Shigella flexneri, Multiplex PCR, Clinical isolates, Pic gene, HeLa cell gentamicin protection assay, Mouse sereny tests

\section{Background}

Bacteria of the genus Shigella are fastidious Gram-negative organisms that cause an estimated 164.7 million cases of shigellosis annually worldwide, and are responsible for 1.1 million deaths [1]. Shigellosis is an acute intestinal infectious disease. Its symptoms range from mild watery diarrhea to a life-threatening dysenteric syndrome with blood, mucus and pus in stools [2-4]. The severity of the disease depends on the virulence of the infecting strain. Therefore, clinical diagnosis tests for Shigellosis should not only focus on the determination

\footnotetext{
* Correspondence: xjcheng@shmu.edu.cn; dqu@shmu.edu.cn ${ }^{1}$ Department of Medical Microbiology and Parasitology, School of Basic Medical Sciences, Fudan University, No. 138 Yixueyuan Road, Shanghai 200032, China

${ }^{2}$ Key Laboratory of Medical Molecular Virology of Ministries of Education and Health, Institute of Medical Microbiology and Institutes of Biomedical Sciences, School of Basic Medical Sciences, Fudan University, No. 138 Yixueyuan Road, Shanghai 200032, China

Full list of author information is available at the end of the article
}

of the strain's biochemical and serological types, but also on the determination of the strain's virulence. Based on biotyping, the Shigella genus contains four species with 48 serotypes (including subgroups). In China, Shigella flexneri 2a (S. flexneri 2a) is the predominant subgroup [2].

To simultaneously, effectively, and rapidly detect the pathogen and determine its virulence, three chromosomeand plasmid-encoded virulence genes (ipaH, ial, and set1B) [3,5-7] were chosen to assist in the development of a multiplex PCR (mPCR) assay. ipaH is present on both the chromosome and on the large Shigella virulence plasmid. Therefore, $i p a H$ is considered a stable PCR target for pathogen identification [8-11]. The ial gene is located in the cell-entry region of the large virulence plasmid that encodes an important part of the molecular machinery required for bacterial invasion and intracellular survival [4,12-14]. This region is bracketed by insertion-like (IS) elements IS100 and IS600, with a high tendency for automatic deletion $[4,13,15,16]$. Detection based on ial 
provides some information pertaining to bacterial virulence but can easily generate false negative results $[4,17]$. The set $1 B$ gene is located on pathogenicity island 1 (PAI1) of the chromosome and encodes Shigella enterotoxin 1 subunit B. Enterotoxin 1 causes the watery phase of diarrhea in Shigellosis $[6,18,19]$. Studies have shown that set1B is present exclusively in $S$. flexneri 2 a $[6,18,19]$. An mPCR system should be able to determine, in a single reaction, whether the genes related to pathogenesis of a particular Shigella strain are encoded on the chromosome or the plasmid, and also to determine the serotype of a particular strain $[4,5]$.

The S. flexneri 2a pic gene, which is located at an unstable chromosomal site of S. flexneri 2a PAI-1, is spontaneously deleted at a low frequency [20]. Previous studies have shown that the pic and set $1 B$ loci are overlapping genes encoded on opposite strands, and $\operatorname{set} 1 B$ is within pic [21]. The Pic protein is a $116 \mathrm{kDa}$ autotransporter protein, secreted by the serine protease auto-transporter from members of the Enterobacteriaceae family [21,22]. To date, pic has only been found in enteroaggregative Escherichia coli (EAEC), uropathogenic E. coli (UPEC) and S. flexneri 2a. Pic has been shown to exhibit hemagglutination and mucinolytic activities in vitro [21-24]. However, it has also been shown that Pic is unable to elicit a cytotoxic effect in the HT29-C1 and HEp-2 epithelial cell lines [24,25].

The major aims of our study were to detect and determine the strain of the Shigella pathogen and determine its virulence. We also investigated whether attenuation of SF51 virulence correlated to the loss of pic, by constructing a pic-deleted mutant and two complementation strains.

\section{Methods \\ Ethics}

All procedures performed on mice were conducted according to national (Regulations for the Administration of Affairs Concerning Experimental Animals, China) and international guidelines (NIH Guide for the Care and Use of Laboratory Animals) and were approved by the Institutional Animal Care and Use Committee (IACUC) of Shanghai Medical College, Fudan University (IACUC Animal Project Number 20090601-QU).

Bacterial strains, plasmids, media and growth conditions Clinical isolates $(n=86)$ of $S$. flexneri were isolated from an epidemic site in Zhengding (Hebei Province, China). Serotyping of the strains was carried out by the Bacteriological Unit at Huashan Hospital (Shanghai, China). The S. flexneri 2a 301 (SF301; GenBank Accession No. AE005674) strain was provided by Dr. Jianguo Xu (Chinese Center for Disease Control and Prevention, Beijing, China). SF301 was isolated in 1984 from the Changping District of
Beijing. The affected subject exhibited a severe acute clinical manifestation of Shigellosis. The complete genome of SF301 was sequenced and has since been used as a reference strain for S. flexneri 2a in China. E. coli ATCC 25922 was provided by Dr. Bijie Hu from Zhongshan Hospital (Shanghai, China). E. coli SM10 $\lambda$ pir and plasmid pSB890 were provided by Dr. Daoguo Zhou from Purdue University (West Lafayette, IN, USA). The pSC plasmid was modified from pREP4 (Qiagen, Hilden, Germany), which contains a p15A origin of replication and a kanamycin resistance gene. E. coli DH5 $\alpha$ was purchased from Invitrogen (Carlsbad, CA, USA). S. flexneri and E. coli were grown at $37^{\circ} \mathrm{C}$ in Luria-Bertani (LB) medium (Oxoid, Wesel, Germany). All bacterial strains were grown on Salmonella-Shigella (SS) agar (Oxoid) before being transferred to an LB agar plate. Strains were then incubated overnight at $37^{\circ} \mathrm{C}$, then stored at $-20^{\circ} \mathrm{C}$ in $\mathrm{LB}$ broth containing $15 \%$ glycerol.

\section{Screening of clinical specimens by MPCR}

The ipaH, ial, and set1B genes were detected by MPCR with primers designed according to the sequences of these genes in SF301 (Table 1) [3,5,7]. Clinical S. flexneri isolates $(n=86)$ were tested using $\mathrm{mPCR}$. The $\mathrm{mPCR}$ mixture $(20 \mu \mathrm{L})$ consisted of $1.8 \times$ PCR buffer $(3 \mathrm{mM}$ $\mathrm{MgCl}_{2}, 130 \mu \mathrm{M}$ dNTP; Invitrogen), $0.5 \mu \mathrm{M}$ ial primer, $0.3 \mu \mathrm{M}$ ipaH primer, $0.3 \mu \mathrm{M}$ set $1 B$ primer, $1 \mathrm{U}$ of Taq DNA polymerase (Invitrogen), and $10 \mu \mathrm{L}$ of bacterial lysate. Thermal cycling conditions involved an initial denaturation step at $95^{\circ} \mathrm{C}$ for $5 \mathrm{~min}$, followed by 30 cycles of $94^{\circ} \mathrm{C}$ for $1 \mathrm{~min}, 56^{\circ} \mathrm{C}$ for $1 \mathrm{~min}$, and $72^{\circ} \mathrm{C}$ for $2 \mathrm{~min}$, and a final extension step at $72^{\circ} \mathrm{C}$ for $7 \mathrm{~min}$ after the $30^{\text {th }}$ cycle.

\section{Plaque formation tests on HeLa cells}

Twelve strains containing ipaH, ial and $\operatorname{set} 1 \mathrm{~B}$ were further tested to determine their virulence in HeLa cells (ATCC CCL-2) using a plaque formation test [26]. HeLa cells were grown in 24-well tissue culture plates until they formed semi-confluent monolayers. The culture medium used was RPMI1640 supplemented with 10\% fetal calf serum (FCS), and 1\% penicillin-streptomycin; and cultures were incubated at $37^{\circ} \mathrm{C} / 5 \% \mathrm{CO}_{2}$. Cells were washed three times with phosphate-buffered saline (PBS), and bacteria added to the semi-confluent HeLa cultures at a multiplicity of infection (MOI) of 100. After incubating at $37^{\circ} \mathrm{C}$ for $90 \mathrm{~min}$, growth medium containing $5 \%(\mathrm{w} / \mathrm{v})$ agar and $20 \mu \mathrm{g} / \mathrm{mL}$ gentamicin was poured into the 24well plates, then incubated at $37^{\circ} \mathrm{C} / 5 \% \mathrm{CO}_{2}$ for $72 \mathrm{~h}$. HeLa cells were inoculated with SF301 as a positive control, and with E. coli ATCC 25922 as a negative control.

Sequence and analysis of virulence genes on PAI-1 of SF51 SF51 genomic DNA was extracted using a QIAamp DNA Mini Kit (Qiagen). PCR primers for amplification 
Table 1 Sequences of oligonucleotide primers used in this study

\begin{tabular}{|c|c|c|c|c|}
\hline Target gene & $\begin{array}{l}\text { Gene position on SF301 genome } \\
\text { or virulent plasmid pCP301 }\end{array}$ & Primer* & Primer sequence $\left(5^{\prime} \rightarrow 3^{\prime}\right)$ & $\begin{array}{l}\text { Length } \\
\text { (bp) }\end{array}$ \\
\hline \multicolumn{5}{|c|}{ Primers for detection of virulence-associated genes of $S$. flexneri by mPCR } \\
\hline \multirow[t]{2}{*}{ ipaH } & $1422225-1422835 * *$ & ipaH-F & CCTTGACCGCCTTTCCGATA & 611 \\
\hline & & ipaH-R & CAGCCACCCTCTGAGAGTACT & \\
\hline \multirow[t]{2}{*}{ ial } & $133550-133869^{* * *}$ & ial-F & CTGGATGGTATGGTGAGG & 320 \\
\hline & & ial-R & CCAGGCCAACAATTATTTCC & \\
\hline \multirow[t]{2}{*}{$\operatorname{set} 1 B$} & $3069523-3069669^{* *}$ & set1B-F & GTGAACCTGCTGCCGATATC & 147 \\
\hline & & set1B-R & ATTTGTGGATAAAAATGACG & \\
\hline \multicolumn{5}{|c|}{ Primers for amplifying int, orf $30, \operatorname{sig} A$ and pic on PAI-1 of S. flexneri $2 a$} \\
\hline \multirow[t]{2}{*}{ int } & $3052736-3053998^{* *}$ & int- $F$ & ATGGCACTGACTGACGCAAA & 400 \\
\hline & & int- $R$ & TGCCGATAAAGGGGAAAACG & \\
\hline \multirow[t]{2}{*}{ orf30 } & $3096187-3097975^{* *}$ & orf30-F & CTTATCACTGAGCGTCTGGT & 1,102 \\
\hline & & orf30-R & GTGAAATTCCTGCCTCAATA & \\
\hline \multirow[t]{2}{*}{$\operatorname{sig} A$} & $3060437-3064294^{* *}$ & $\operatorname{sigA-F}$ & AGTCATATTACAGGTGGATTAG & 1,866 \\
\hline & & $\operatorname{sig} A-R$ & TATACTCAGGGTTGCGTIT & \\
\hline \multirow[t]{2}{*}{ pic } & $3067737-3070949 * *$ & pic- $\mathrm{F}$ & AGAACATATACCGGAAATTC & 1,219 \\
\hline & & pic-R & ACCCTGACGGTGAATAAACT & \\
\hline \multicolumn{5}{|c|}{ Primers for homologous recombination to construct pic knockout strain } \\
\hline \multirow[t]{2}{*}{ upstream of pic } & $3067236-3067745^{* *}$ & uppic-F-Notl & AAGCGGCCGCCATAGCAGACTGGCCGGTCAACC & 520 \\
\hline & & uppic-R-Xbal & CCTCTAGAATGTTCTGATGTGGGGGTAAAGGGC & \\
\hline \multirow{2}{*}{$\begin{array}{l}\text { downstream } \\
\text { of pic }\end{array}$} & $3071850-3072358 * *$ & downpic-F-Xbal & CCTCTAGAATTCACTATGGATTCTCCATGAT & 517 \\
\hline & & downpic-R-BamHI & AAGGATCCCGTCGTCCGTCTGGCACC & \\
\hline upstreamof pic & $3066436-3072733^{* *}$ & Upuppic-F & GCTGAACTGC TGGAGCCGCT & 1176 \\
\hline $\begin{array}{l}\text { downstream } \\
\text { of pic }\end{array}$ & & Downdown Pic-R & CAGCGGCGAAATACTGTACC & \\
\hline \multirow{2}{*}{$\begin{array}{l}\text { pic coding frame } \\
\text { work }\end{array}$} & $3067737-3070949^{* *}$ & pic-pSC-F-PfMII & AAACCATCGAATGGATGCAGGACGATTTCGATGCCCCCGTAGAC & 3,213 \\
\hline & & pic-pSC-R-Acll & TTIAACGTTCAGAACATATACCGGAAATTCGCGTT & \\
\hline
\end{tabular}

${ }^{*} \mathrm{~F}$, forward primer; $\mathrm{R}$, reverse primer. **SF301 GenBank Accession No. AE005674. ***SF301 large virulent plasmid pCP301 GenBank Accession No. AF386526. Underlined sequences represent restriction endonuclease sites.

of pic, sigA, int and orf30 from PAI-1 of the SF51 clinical isolate were designed according to the SF301 sequence. Amplicons were cloned into a pCR-XL-TOPO vector using a TOPO $^{\circledR}$ XL PCR Cloning Kit (Invitrogen), and the inserts were sequenced by Sangon Biotech (Shanghai, China) Co. Ltd, then identified using the standard nucleotide basic local alignment search tool (BLASTn; NCBI).

\section{Construction of SF301- $\Delta$ pic}

The upstream and downstream portions of pic were amplified by PCR. Primers uppic-F-NotI and uppic-R-XbaI (Table 1) were used to amplify the upstream fragment of pic, with primers downpic-F-XbaI and downpic-R-BamHI (Table 1) used to amplify the downstream fragment. The amplified downstream fragment of pic was digested with $X b a \mathrm{I}$ and $\mathrm{BamHI}$ and ligated into pSB890 which had been cut with the same restriction endonucleases [27]. We designated the resulting plasmid pSB890-pic downstream. The amplified upstream pic fragment was digested with NotI and $X b a \mathrm{I}$ and ligated into pSB890-pic downstream that had been digested with NotI and $X b a \mathrm{I}$. The resulting vector was designated pSB890- $\Delta$ pic and transformed into $E$. coli SM10 $\lambda$ pir cells, then introduced into SF301 through a bacterial conjugation test. After culturing on a sucrose LB agar plate at $22^{\circ} \mathrm{C}$, sucrose-tolerant colonies were screened using Shigella-specific minimal medium [7] and a PCR employing primers Upuppic-F and Downdownpic-R (Table 1). The mutant strain with the pic deletion was identified by sequencing and named SF301- $\Delta$ pic. 


\section{Construction of complementation strains SF301- $\Delta$ pic/pPic and SF51/pPic}

A plasmid containing pic was constructed using pSC modified from pREP4. The pic gene was amplified from SF301 genomic DNA using PCR. The PCR primers used were pic-pSC-F-PfMlI and pic-pSC-R-AclI (Table 1). Amplicons were inserted into $\mathrm{pSC}$, creating $\mathrm{pSC}$-pic, which was verified by restriction enzyme digestion and nucleic acid sequencing. Verified pSC-pic was transformed into SF301- $\Delta$ pic and SF51, resulting in SF301- $\Delta$ pic/pPic and SF51/pPic, respectively.

\section{S. flexneri growth curves}

The growth curves of $S$. flexneri 2a strains were determined by measuring the optical density at $600 \mathrm{~nm}$ $\left(\mathrm{OD}_{600}\right)$ as described previously [28]. Briefly, overnight cultures were diluted 1:200 and incubated at $37^{\circ} \mathrm{C}$ with shaking $(220 \mathrm{rpm})$. Samples $(1 \mathrm{~mL})$ of the bacterial cultures were taken every $30 \mathrm{~min}$ over $16 \mathrm{~h}$ and OD measured. Growth curves were created by plotting $\mathrm{OD}_{600}$ against incubation time (h).

\section{S. flexneri HeLa cell invasion assays}

$S$. flexneri cell invasion assays were used to test the virulence of a SF51 clinical strain without $\operatorname{set} 1 B, \mathrm{SF} 301-\Delta$ pic, wild-type SF301, SF301- $\Delta$ pic/pPic and SF51/pPic. The ability of bacteria to invade HeLa cells was determined using a gentamicin protection assays [29]. HeLa cells were grown in 6-well tissue culture plates in DMEM supplemented with $10 \%$ FCS and incubated at $37^{\circ} \mathrm{C} / 5 \%$ $\mathrm{CO}_{2}$ until they formed semi-confluent monolayers. SF51, SF301- $\Delta$ pic, SF301- $\Delta$ pic/pPic, SF51/pPic and SF301 were individually added to semi-confluent HeLa cells at an MOI of 100. Bacteria were diluted and plated on LB agar plates. Colony-forming units (CFUs) were counted and added to HeLa cells. Plates were centrifuged at $900 \times g$ for $5 \mathrm{~min}$. After incubating at $37^{\circ} \mathrm{C}$ for $90 \mathrm{~min}$, cells were washed three times with PBS, and gentamicin added to the medium at a final concentration of $10 \mu \mathrm{g} / \mathrm{mL}$. The mixture was then incubated for $20 \mathrm{~min}$ at $37^{\circ} \mathrm{C}$. HeLa cells in each well were lysed with $1 \mathrm{~mL}$ of PBS containing $0.1 \%$ Triton X-100 for $10 \mathrm{~min}$ at room temperature. Lysates were diluted and plated onto LB agar plates in triplicate. Colonies that grew on LB plates were counted. Results were expressed as the number of bacteria recovered from gentamicin-treated cells divided by the number of inoculated bacteria added to the cell. Cells inoculated with $E$. coli ATCC 25922, an avirulent strain, were the negative controls. Cell invasion assays were performed in triplicate for each strain, and the assay repeated twice.

\section{Sereny tests and pathohistological examination}

A mouse Sereny test was used to evaluate the virulence of all strains we examined in this study, as described by
Murayama [30]. A single red colony of S. flexneri on Congo red agar [Tryptic soy broth (Oxoid), 1.5\% (w/v) agar and $0.01 \%(\mathrm{w} / \mathrm{v})$ Congo red] was inoculated into $\mathrm{LB}$ broth at $37^{\circ} \mathrm{C}$ for $8 \mathrm{~h}$ with constant shaking. Female $\mathrm{BALB} / \mathrm{c}$ mice (4-5-weeks-old) were infected with $1 \times$ $10^{8}$ CFUs per eye ( $n=4$ eyes, two mice in each group). Symptoms and signs of keratoconjunctivitis in mice infected with bacteria were observed at 24, 48, 72, and $96 \mathrm{~h}$ post-inoculation [28,30]. Eyes inoculated with $E$. coli ATCC 25922 and normal saline (NS) served as the negative controls. The invasiveness of bacteria was scored according to the following system: '-' indicates no inflammation, and an infection level score of 0 ; ' \pm ' is indicative of low levels of keratoconjunctivitis, and an infection level score of 0.5 ; ' + ' indicates slight conjunctival inflammation with eyelid edema, and an infection level score of 1 ; ' ++ ' indicates mild keratoconjunctivitis with eyelid edema, increased tear film evaporation and periocular hair loss, and an infection level score of 2 ; and ' +++ ' indicating fully developed keratoconjunctivitis with eyelid swelling, periocular hair loss, blepharophimosis, conjunctival follicles and purulent discharge, and an infection level score of 3 . At 24, 48, 72, and $96 \mathrm{~h}$ post-inoculation, mice were euthanized and the eyes removed and fixed in $4 \%$ formalin in PBS ( $\mathrm{pH}$ 7.2). After hemotoxylin and eosin (H\&E) staining, eye sections were examined using a light microscope.

\section{Statistical analysis}

Experimental data were analyzed with SPSS and comparisons made using Student's $t$-test. Differences with a $P$-value less than 0.05 were considered statistically significant.

\section{Results}

\section{Detection of ipaH, ial, and set1B in S. flexneri clinical} isolates

The ipaH gene was detected in all 86 S. flexneri clinical isolates, whereas ial was detected in 45 isolates $(52.3 \%)$, and set $1 B$ detected in 69 isolates $(80.2 \%)$. Amplicons for $i p a H$, ial and set1B were not seen from E. coli ATCC 25922 samples. All three genes were detected in the SF301 positive control.

\section{HeLa cell invasion of $S$. flexneri clinical isolates}

Nine isolates in our study contained all three genes, one SF68 isolate contained ipaH and $\operatorname{set} 1 B$, one SF51 isolate had ipaH and ial, and one SF36 isolate contained only ipaH (Table 2). The nine isolates that contained all three virulence-associated genes demonstrated high invasive ability in HeLa cells (>200 plaques/well). In HeLa cells, SF68 and SF36 were less invasive resulting in 4 and 2 plaques/well, respectively. SF51 lacked set1B but retained $\mathrm{ial}$, and showed a decrease in invasiveness (20 plaques/ well; Table 2). Using PCR and nucleotide sequencing, it 
Table 2 Invasion of HeLa cells by S. flexneri clinical isolates as determined by plaque formation tests

\begin{tabular}{|c|c|c|c|c|}
\hline \multicolumn{3}{|c|}{ Gene detected by mPCR } & \multirow{2}{*}{$\begin{array}{l}\text { Number } \\
\text { of strains }\end{array}$} & \multirow{2}{*}{$\begin{array}{l}\text { Plaque formation } \\
\text { number (per well)* }\end{array}$} \\
\hline$\overline{\text { ipaH }}$ & ial & $\operatorname{set} 1 B$ & & \\
\hline+ & + & + & 9 & $>200 \pm 16$ \\
\hline+ & + & - & 1 (SF51) & $20 \pm 5$ \\
\hline+ & - & + & 1 (SF68) & $4 \pm 2$ \\
\hline+ & - & - & 1 (SF36) & $2 \pm 1$ \\
\hline
\end{tabular}

* Values represent the mean \pm standard deviation of three wells.

was shown that SF51 lacked the entire pic gene on PAI-1, but harbored sigA and other significant open reading frames (Figure 1).

HeLa cell invasion of SF301 and mutants

The growth curves for SF51, SF301- $\Delta$ pic, SF301, SF301- $\Delta$ pic/pPic and SF51/pPic were similar under aerobic growth conditions (Figure 2). Gentamicin protection tests on HeLa cells revealed that the cell invasion ratio for clinical isolate SF51 with standard strain SF301 decreased by 34\%, while the invasion ratio for SF301- $\Delta$ pic compared with SF301 decreased by $61 \%$ (Figure 3A). The invasion abilities were partially recovered by the introduction of pic into deleted mutant SF301- $\Delta$ pic, which increased the ratio by $31 \%$ (to a final cell invasion ratio of $51 \%$, Figure 3A). The invasion abilities of SF51/pPic increased by $59 \%$ compared with SF51, with cell invasion ratios of $35 \%$ and $22 \%$, respectively (Figure $3 \mathrm{~B}$ ). The E. coli ATCC 25922 strain was not found to invade HeLa cells.

\section{Mouse Sereny tests and pathohistological examination} Mouse Sereny tests confirmed the results of the cell invasion tests. Mild presentation of keratoconjunctivitis was observed $24 \mathrm{~h}$ after mice were infected with SF301. Symptoms included eyelid edema, increased tear film evaporation and periocular hair-loss that we scored as either + or ++ , with an average infection level score of 1.5. This developed into severe keratoconjunctivitis with maximal blepharophimosis at $48 \mathrm{~h}$ that we rated +++ , and an average infection level score of 2.8. Keratoconjunctival inflammation continued for $96 \mathrm{~h}$ post-inoculation with SF301 (Figure 4). Both the isolated and constructed picdeletion mutants induced lower levels of inflammation in the eyes of mice than for SF301 (Figure 4). At $48 \mathrm{~h}$ postinoculation, the pathogenicity of SF301- $\Delta$ pic in mouse
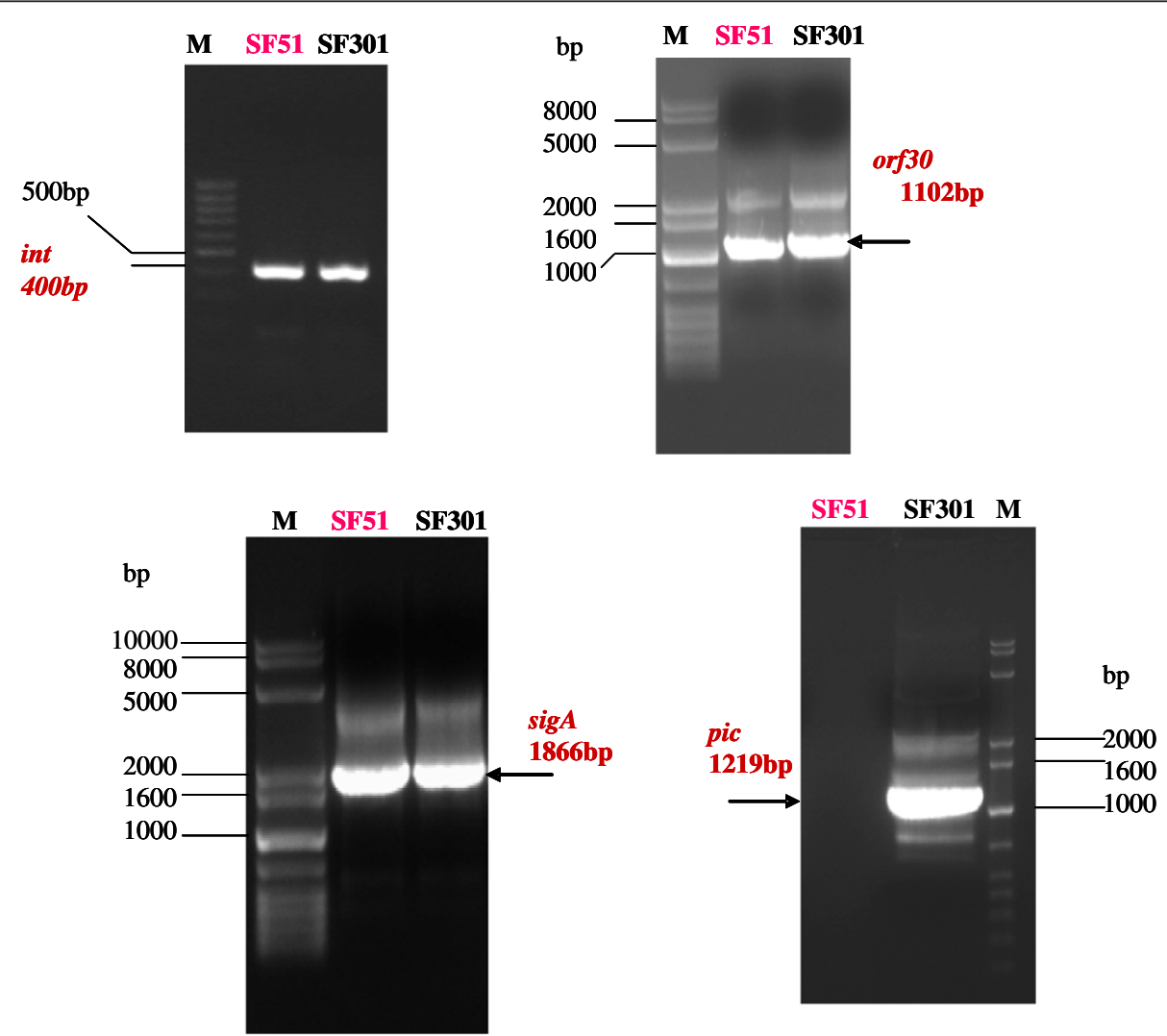

Figure 1 Amplicons from SF51 int, orf30, sigA and pic. Specific amplicons for (A) int; (B) orf30; (C) sigA; and (D) pic. The target genes int, orf30 and sigA were amplified from SF51 DNA but pic was not. All four target genes were amplified from the SF301 positive control. The sequence of all PCR products was confirmed by nucleic acid sequencing. 


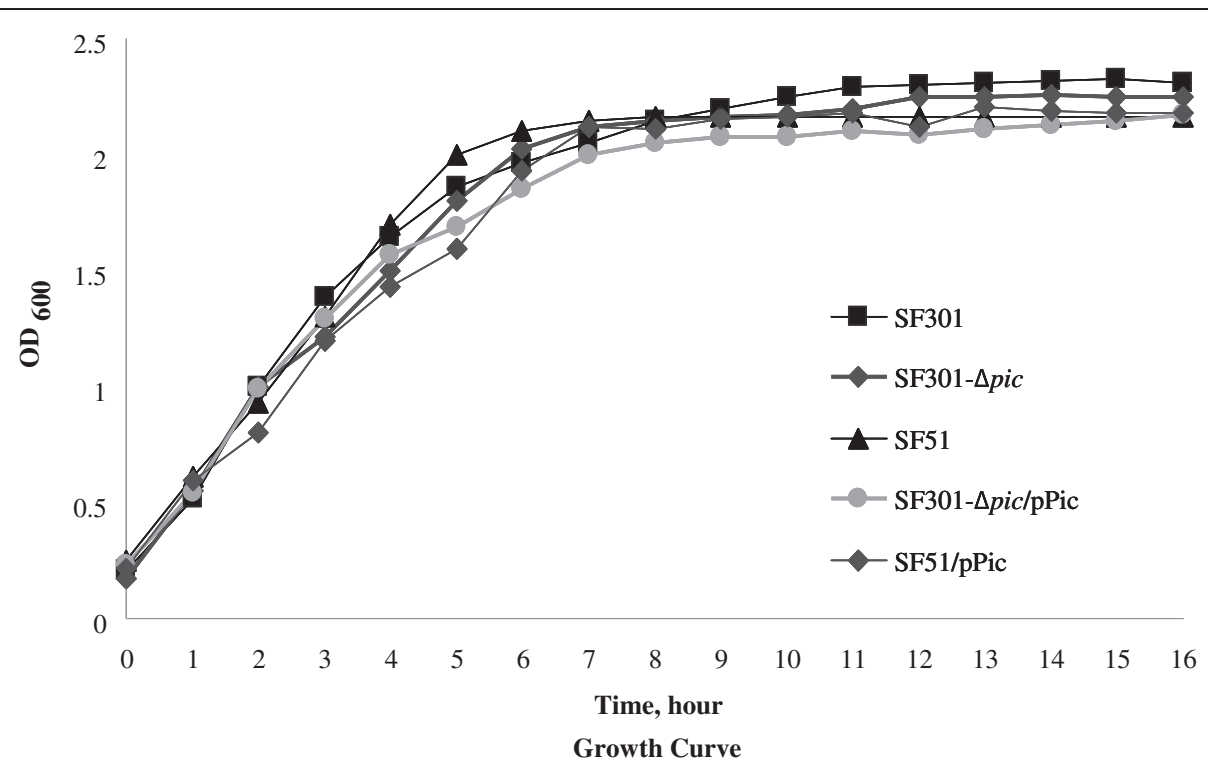

Figure 2 Growth curves for SF301 and the pic mutants (SF51, SF301- $\Delta$ pic, SF301- $\Delta$ pic/pPic and SF51/pPic).

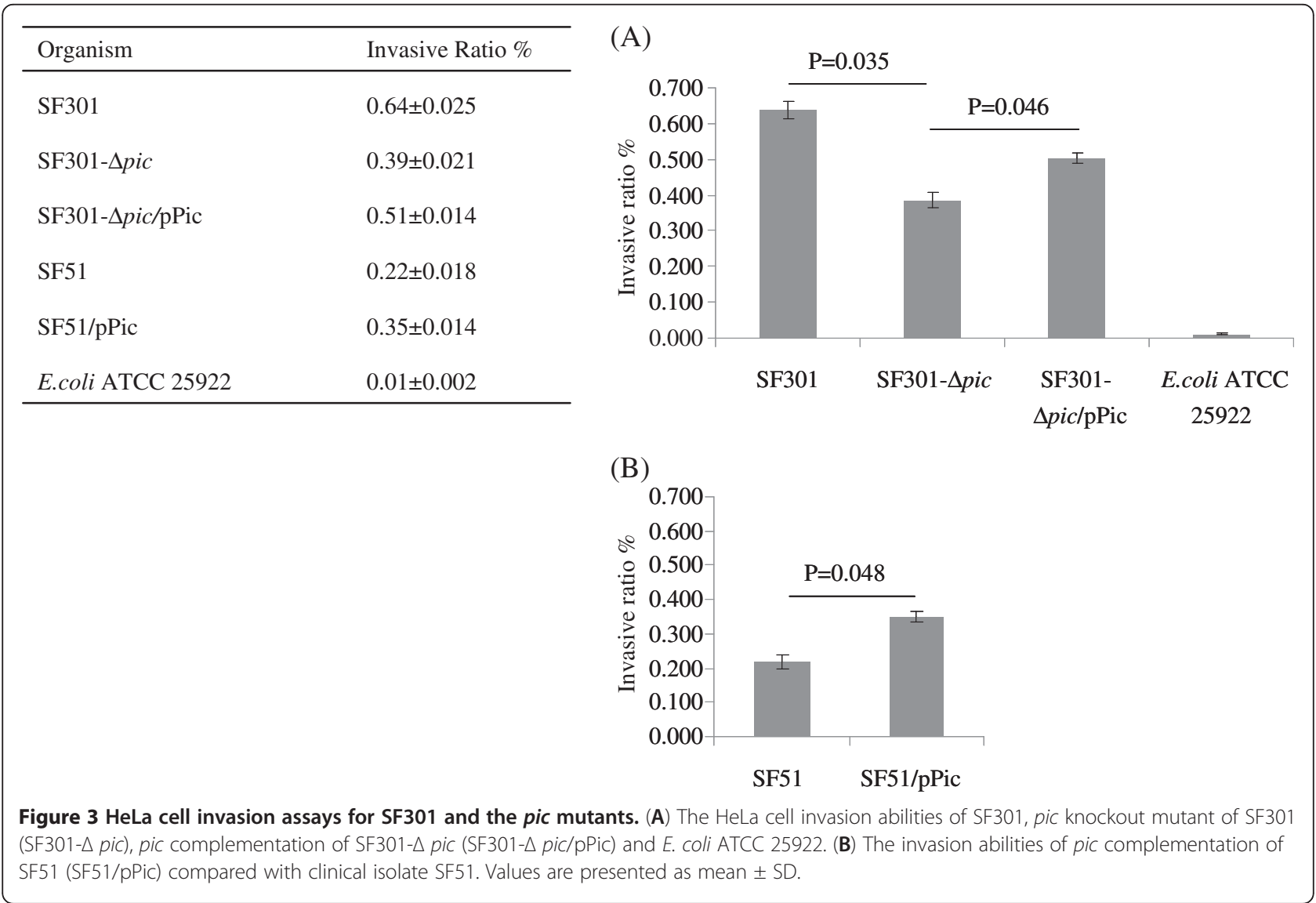




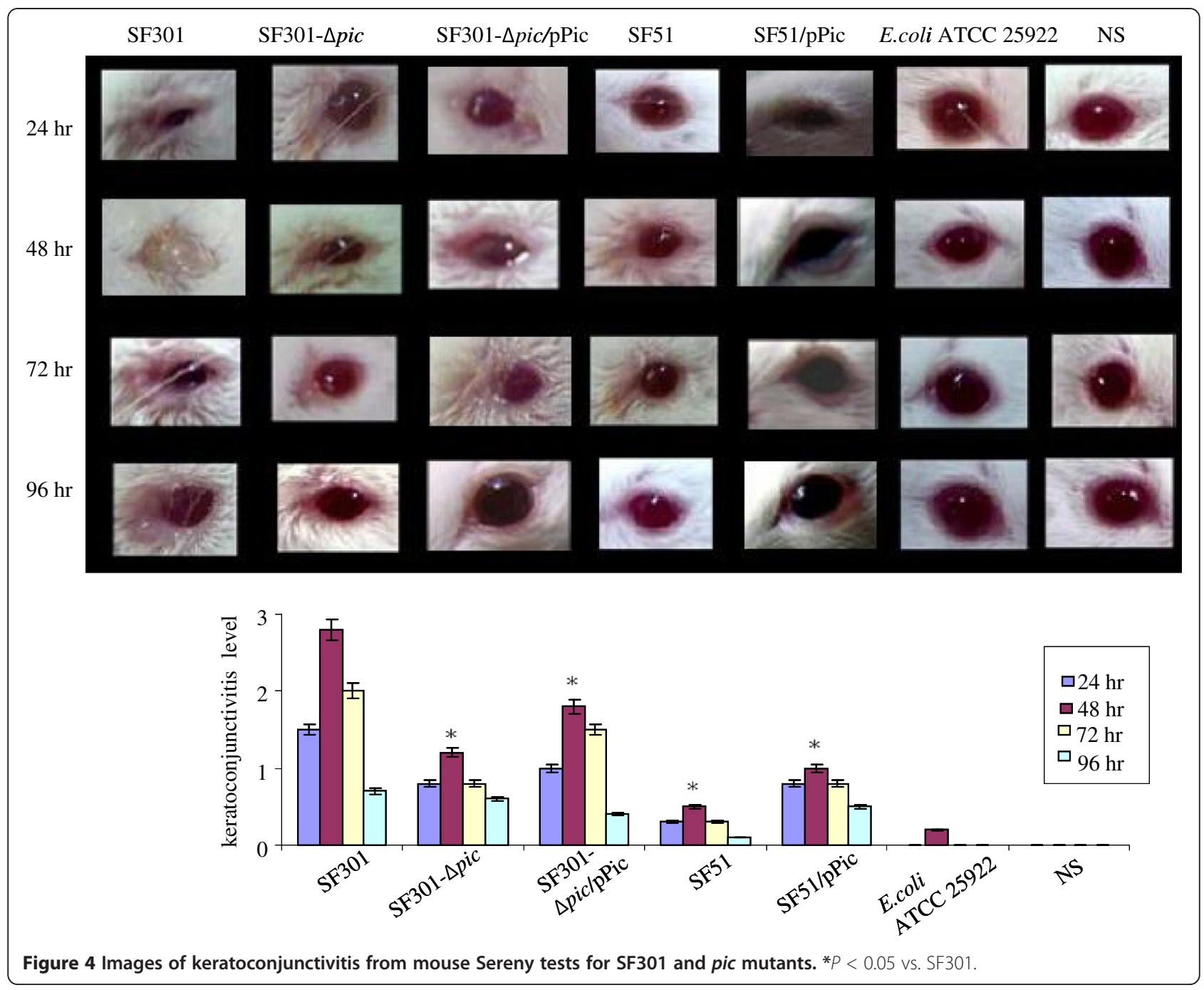

eyes were assessed as + or ++ with an average infection level scores up to 1.2 ; for SF51, pathogenicity was rated \pm or + with an average infection level score less than 0.6.

Virulence was partially recovered by introducing the complementary pSC-pic into the deletion mutants. At $48 \mathrm{~h}$ post-inoculation the pathogenicity of SF301- $\Delta$ pic/ pPic was rated at + or ++ with an average infection level score 1.9; SF51/pPic pathogenicity was + or ++ with average infection level scores of 1.2. At $48 \mathrm{~h}$ post-infection, inflammatory reactions were not observed in the normal saline negative controls $(-, 0)$. However, E. coli ATCC 25922 slight edema $( \pm)$ in a single eyelid at $48 \mathrm{~h}$ postinfection with an average infection level score of 0.3 .

Light microscopy assessment at $48 \mathrm{~h}$ post-infection revealed typical symptoms of SF301 infection. These included limited invasion, corneal epithelial thickening and loss, along with mild, moderate, or severe ulcers. Both pic-deletion mutants showed fewer pathologic changes following H\&E staining compared with SF301 (Figure 5).

\section{Discussion}

Shigella pathogenicity is a multigenic phenomenon involving the participation of genes on the unstable large virulence plasmid and chromosomal PAIs [12-14,17,28,31-34]. Mobile genes encode key factors that help Shigella invade tissue and maintain its intracellular viability [13,17,35-38]. The pathogenicity of the strain decreases markedly once the mobile genes are deleted $[4,32,33]$.

Several studies have been conducted to detect virulence genes in Shigella by mPCR, targeting ipaH, ial, and $r f c$ or $s t x 1$ for serotype identification [3,5,7,39]. In 2005, Thong [5] first described a new MPCR system to detect $S$. flexneri 2a by targeting four virulence genes (ipaH, ial, set $1 A$ and set $1 B$ ). This mPCR system was able to determine, in a single reaction, whether genes related to pathogenesis of a particular Shigella strain are associated with the chromosome or plasmid, and whether the serotype of the particular strain can be grouped under S. flexneri 2a $[4,5]$. In our present study, Thong's mPCR system was modified to identify S. flexneri $2 \mathrm{a}$ 


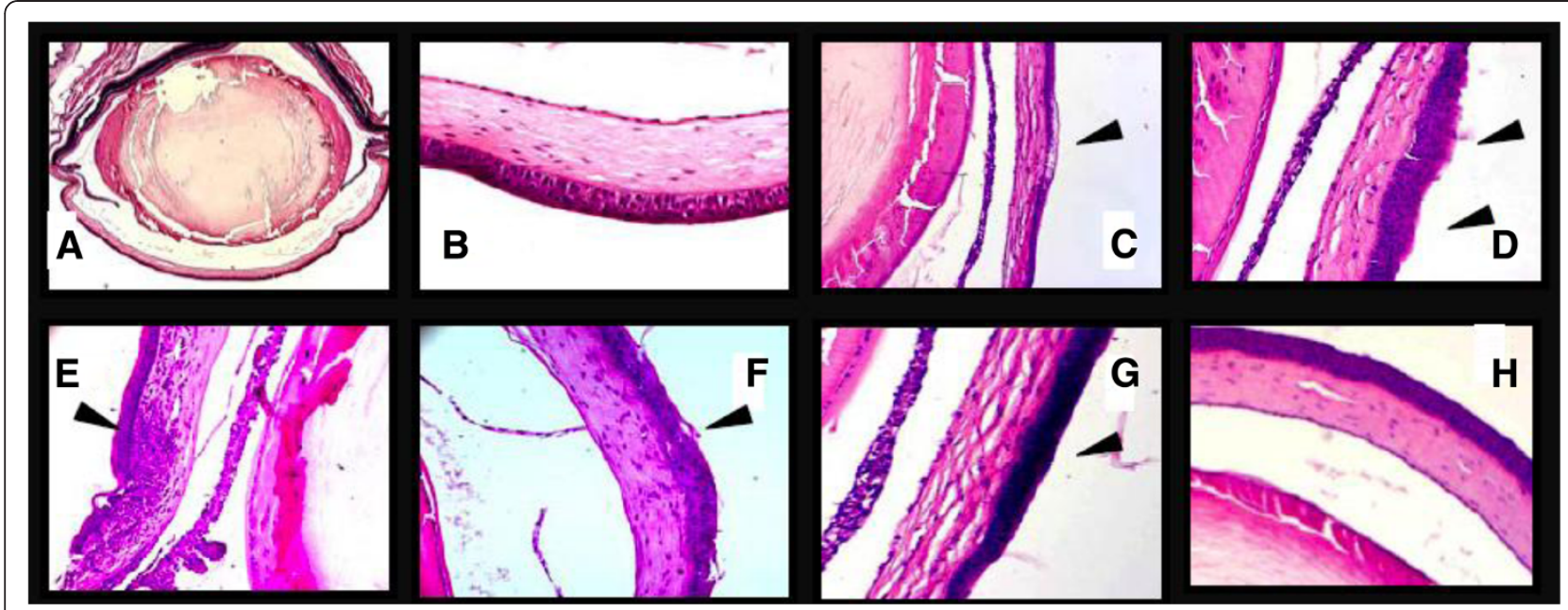

Figure 5 Histological features of mouse corneas following Sereny tests with SF301 and pic mutants. (A, B) Following inoculation with normal saline, normal corneal epithelium with many layers arranged in an orderly manner can be seen (A: $\times 50$ magnification; $\times \times 400$ magnification). (C) After infection with SF301, the corneal epithelium was thinner than that of the control, and vesicular changes (arrowheads) were observed (×100 magnification). (D) Corneal epithelial edema was observed (arrowheads; $\times 200$ magnification). (E) Polymorphic nuclear neutrophilic activity was observed (arrowheads; $\times 200$ magnification). (F) Corneal epithelial derangement and detachment were observed (arrowheads; $\times 200$ magnificaiton). (G) After infection with SF301- $\triangle$ pic little damage was observed, but corneal epithelial hyperplasia was noted (arrowheads; $\times 200$ magnification). (H) After infection with SF51, little damage was observed (×200 magnification).

strains and their virulence using only three virulent genes (ipaH, ial, and set1B). We omitted set1A from the mPCR system, as both set $1 B$ and $\operatorname{set} 1 A$ genes have been shown to exist in tandem on PAI-1 of the bacterial chromosome, and they share the same promoter [5,21]. The low prevalence of $\mathrm{ial}(45 / 86,52.3 \%)$ verifies that the cell-entry region on the large virulence plasmid of $S$. flexneri is prone to loss or deletion. The high prevalence of the $\operatorname{set} 1 B$ gene $(69 / 86,80.2 \%)$ verifies that in the rural regions of Zhengding, the isolated epidemic strain of Shigella was S. flexneri 2a. All of our mPCR results were confirmed by serological tests. We confirmed that comparable decreases in virulence occur following the deletion of essential elements in the large virulence plasmid (ipaH and set1B for SF68; and ipaH for SF36) [35-38]. A clinical SF51 isolate was found to retain $i a l$ but had lost set $1 B$, and demonstrated an obvious decrease in HeLa cell invasion. This indicated to us that the chromosome locus around set $1 B$ may influence virulence.

The location of set $1 B$ is known to be in Shigella PAI-1 $[7,20]$, which exists exclusively in S. flexneri 2a. At least four major virulence genes are present in PAI-1 (pic, $\operatorname{set} 1 A$, set $1 B$, and $\operatorname{sig} A$ ). The autotransporter SigA exhibits cytopathic effects on HEp-2 cells [40], and the autotransporter Pic exhibits hemagglutination and mucinolytic activities in vitro [20-23,41-43]. Upstream from pic are two IS elements, IS911 and IS629, followed by pic itself, and then a perD IS element [21]. This implies that pic can be spontaneously deleted.

The upstream element int, downstream element orf30, cytopathic factor gene sigA, and the hemagglutinin gene pic on PAI-1 of SF51 were sequenced to verify whether SF51 lost the whole PAI-1 or only part of the genetic locus around set $1 B$. Our results revealed that the entire pic gene on PAI-1 was deleted in this case, whereas other genes (sigA, int, and orf30) were unaffected (Figure 1). This result also suggests that a decrease in virulence of SF51 is not related to sigA, but may be associated with pic deletion.

To confirm that the decreased virulence phenotype in SF51 was associated with deletion of pic, we knocked out pic from the SF301 strain to produce SF301- $\Delta$ pic. Additionally, complementation strains SF301- $\Delta$ pic/pPic and SF51pic/pPic were constructed to demonstrate that the decreased virulence of SF51 was associated with the deletion of pic. Using gentamicin protection assays, we showed that the Hela cell invasion potential of the pic knockout strains, SF51 and SF301- $\Delta$ pic, was decreased compared with the wild-type SF301 strain. This decreased virulence was partially recovered by introducing pSC-pic.

Previous studies have demonstrated that purified recombinant protein Pic (prepared from E.coli HB101 (pPic1)) is not involved in cytotoxic effects on HT29-C1 and HEp-2 cells [24,25]. However, the findings from our current study show that both the clinical and constructed pic-deleted mutants possessed a decreased tendency for cell invasion compared with SF301. Virulence was partially recovered through the insertion of a complementary pic gene into these deletion mutants. Because Pic did not elicit cytopathic effects on epithelial cells, it may be associated with a less efficient interaction process with host cells, lacking any assistance from 
bacterial effectors. This phenomenon has also been observed by Vidal et al. [44], who examined the EPEC autotransporter EspC. Purified EspC requires a higher concentration $(300 \mu \mathrm{g} / \mathrm{ml}$ vs. $50 \mu \mathrm{g} / \mathrm{ml}$ for other autotransporter cytotoxins) and a longer incubation time $(8 \mathrm{~h}$ vs. $1 \mathrm{~h}$ for EPEC host cells) to produce the same cytotoxic effects as other EPEC isolates. Further studies have confirmed that EspC translocation into epithelial cells results in cytopathic effects in HeLa cells, but require participation of types III and V secretion systems. The mechanism by which Pic is interacted with epithelial cells remains unknown and warrants further study. Further, differences in results observed with Pic regarding decreases in cytopathic effects are likely also associated with other cell lines. Differences in invasion efficiency between Hela cells and HEp-2 cells have been observed for Streptococcus pyrogenes, Campylobacter jejuni and Salmonella typhimurium [45-47]; however, the reasons for these differences remain unclear, and further study is required to clarify this.

The mouse Sereny test is commonly used to the test the invasiveness of Shigella [30]. In our work, the virulence of SF51 and SF301- $\Delta$ pic was obviously decreased. This was partially recovered by the introduction of pSCpic into deletion mutants. Our findings support the conclusion that pic is associated with the invasion potential of S. flexneri 2a.

Harrington et al. [42] used a mouse model treated with streptomycin to show that Pic promotes intestinal colonization by comparing intestinal colonization abilities of wild-type E. coli 042 and pic mutants (E. coli 042 pic:: aph3 and E. coli 042PicS258A). They demonstrated that the constructed mutants (E. coli 042 pic:: aph3 and E. coli 042PicS258A) contained significant defects that adversely affected colonization of mice gastrointestinal tracts compared with E. coli 042. Further work by Harrington et al. suggested that a possible mechanism of promoting intestinal colonization depended on the mucinase activity of Pic. They also showed that this effect is associated with the serine protease catalytic residue in Pic. The research of Harrington et al. supports our findings that Pic is involved in bacterial invasion ability. Whether a decrease in virulence is associated with the mucinase activity of Pic, or other biological activities, should be investigated further.

\section{Conclusions}

Our findings suggest that pic, located on PAI-1 of S. flexneri 2a, plays a role in cell invasion during Shigella infections. Further work is necessary to elucidate how Pic affects host-pathogen interactions, and how Pic assists S. flexneri 2a to invade intestinal epithelial cells and cause cytopathic effects.

\section{Competing interests}

The authors declare that they have no competing interests.

\section{Authors' contributions}

JZ performed the molecular genetic studies, participated in sequence analysis, constructed the pic gene deletion mutant and pic gene complementation strains, carried out mouse Sereny tests and drafted the manuscript. XC participated in mouse Sereny tests and conducted H\&E staining. XL conducted MPCR tests and performed HeLa cell gentamicin protection assays. LQ and YW participated in the design of the study, performed statistical analysis and edited the manuscript. DQ and YW participated in the design and coordination of the study, and helped to draft and edit the manuscript. All authors read and approved the final version of the manuscript.

\section{Acknowledgements}

This work was supported by grants from the National Key Scientific Program (2009ZX10004-104), National S\&T Major Project of the Ministry of Science and Technology of China (2012ZX09301002005004, 2012ZX10004401) and National Natural Science Foundation of China (21276074,81101214 and 81271791).

\section{Author details}

${ }^{1}$ Department of Medical Microbiology and Parasitology, School of Basic Medical Sciences, Fudan University, No. 138 Yixueyuan Road, Shanghai 200032, China. ${ }^{2}$ Key Laboratory of Medical Molecular Virology of Ministries of Education and Health, Institute of Medical Microbiology and Institutes of Biomedical Sciences, School of Basic Medical Sciences, Fudan University, No. 138 Yixueyuan Road, Shanghai 200032, China.

Received: 11 February 2012 Accepted: 30 January 2013

Published: 8 February 2013

\section{References}

1. Kotloff KL, Winickoff JP, Ivanoff B, Clemens JD, Swerdlow DL, Sansonetti PJ, Adak GK, Levine MM: Global burden of Shigella infections: implications for vaccine development and implementation of control strategies. Bull World Health Organ 1999, 77(8):651-666

2. Wang XY, Tao F, Xiao D, Lee H, Deen J, Gong J, Zhao Y, Zhou W, Li W, Shen $B$, et al: Trend and disease burden of bacillary dysentery in China (1991-2000). Bull World Health Organ 2006, 84(7):561-568.

3. Melito PL, Woodward DL, Munro J, Walsh J, Foster R, Tilley P, Paccagnella A, Isaac-Renton J, Ismail J, Ng LK: A novel Shigella dysenteriae serovar isolated in Canada. J Clin Microbiol 2005, 43(2):740-744.

4. Schroeder GN, Hilbi H: Molecular pathogenesis of Shigella spp.: controlling host cell signaling, invasion, and death by type III secretion. Clin Microbiol Rev 2008, 21(1):134-156.

5. Thong KL, Hoe SL, Puthucheary SD, Yasin RM: Detection of virulence genes in Malaysian Shigella species by multiplex PCR assay. BMC Infect Dis 2005, 5:8.

6. Vargas M, Gascon J, Jimenez De Anta MT, Vila J: Prevalence of Shigella enterotoxins 1 and 2 among Shigella strains isolated from patients with traveler's diarrhea. J Clin Microbiol 1999, 37(11):3608-3611.

7. Rajakumar K, Sasakawa C, Adler B: Use of a novel approach, termed island probing, identifies the Shigella flexneri she pathogenicity island which encodes a homolog of the immunoglobulin A protease-like family of proteins. Infect Immun 1997, 65(11):4606-4614.

8. Okuda J, Toyotome T, Kataoka N, Ohno M, Abe H, Shimura Y, Seyedarabi A, Pickersgill R, Sasakawa C: Shigella effector IpaH9.8 binds to a splicing factor U2AF(35) to modulate host immune responses. Biochem Biophys Res Commun 2005, 333(2):531-539.

9. Toyotome T, Suzuki T, Kuwae A, Nonaka T, Fukuda H, Imajoh-Ohmi S, Toyofuku T, Hori M, Sasakawa C: Shigella protein IpaH(9.8) is secreted from bacteria within mammalian cells and transported to the nucleus. J Biol Chem 2001, 276(34):32071-32079.

10. Fernandez-Prada CM, Hoover DL, Tall BD, Hartman AB, Kopelowitz J, Venkatesan MM: Shigella flexneri IpaH(7.8) facilitates escape of virulent bacteria from the endocytic vacuoles of mouse and human macrophages. Infect Immun 2000, 68(6):3608-3619.

11. Rohde JR, Breitkreutz A, Chenal A, Sansonetti PJ, Parsot C: Type III secretion effectors of the IpaH family are E3 ubiquitin ligases. Cell Host Microbe 2007, 1(1):77-83.

12. Sansonetti PJ, Kopecko DJ, Formal SB: Involvement of a plasmid in the invasive ability of Shigella flexneri. Infect Immun 1982, 35(3):852-860. 
13. Sasakawa C, Kamata K, Sakai T, Murayama SY, Makino S, Yoshikawa M: Molecular alteration of the 140-megadalton plasmid associated with loss of virulence and Congo red binding activity in Shigella flexneri. Infect Immun 1986, 51(2):470-475.

14. Buchrieser C, Glaser P, Rusniok C, Nedjari H, D'Hauteville H, Kunst F, Sansonetti $P$, Parsot C: The virulence plasmid pWR100 and the repertoire of proteins secreted by the type III secretion apparatus of Shigella flexneri. Mol Microbiol 2000, 38(4):760-771.

15. Yang F, Yang J, Zhang X, Chen L, Jiang Y, Yan Y, Tang X, Wang J, Xiong Z, Dong J, et al: Genome dynamics and diversity of Shigella species, the etiologic agents of bacillary dysentery. Nucleic Acids Res 2005, 33(19):6445-6458

16. Jin Q, Yuan Z, Xu J, Wang Y, Shen Y, Lu W, Wang J, Liu H, Yang J, Yang F, et al: Genome sequence of Shigella flexneri $2 a$ : insights into pathogenicity through comparison with genomes of Escherichia coli K12 and O157. Nucleic Acids Res 2002, 30(20):4432-4441.

17. Venkatesan MM, Goldberg MB, Rose DJ, Grotbeck EJ, Burland V, Blattner FR: Complete DNA sequence and analysis of the large virulence plasmid of Shigella flexneri. Infect Immun 2001, 69(5):3271-3285.

18. Noriega FR, Liao FM, Formal SB, Fasano A, Levine MM: Prevalence of Shigella enterotoxin 1 among Shigella clinical isolates of diverse serotypes. J Infect Dis 1995, 172(5):1408-1410.

19. Fasano A, Noriega FR, Liao FM, Wang W, Levine MM: Effect of shigella enterotoxin 1 (ShET1) on rabbit intestine in vitro and in vivo. Gut 1997, 40(4):505-511.

20. Al-Hasani K, Rajakumar K, Bulach D, Robins-Browne R, Adler B, Sakellaris H: Genetic organization of the she pathogenicity island in Shigella flexneri 2a. Microb Pathog 2001, 30(1):1-8.

21. Henderson IR, Czeczulin J, Eslava C, Noriega F, Nataro JP: Characterization of pic, a secreted protease of Shigella flexneri and enteroaggregative Escherichia coli. Infect Immun 1999, 67(11):5587-5596.

22. Henderson IR, Nataro JP: Virulence functions of autotransporter proteins. Infect Immun 2001, 69(3):1231-1243.

23. Yen $Y T$, Kostakioti M, Henderson IR, Stathopoulos C: Common themes and variations in serine protease autotransporters. Trends Microbiol 2008, 16(8):370-379.

24. Gutierrez-Jimenez J, Arciniega I, Navarro-Garcia F: The serine protease motif of Pic mediates a dose-dependent mucolytic activity after binding to sugar constituents of the mucin substrate. Microb Pathog 2008, 45(2):115-123

25. Dutta PR, Cappello R, Navarro-Garcia F, Nataro JP: Functional comparison of serine protease autotransporters of enterobacteriaceae. Infect Immun 2002, 70(12):7105-7113.

26. Oaks EV, Wingfield ME, Formal SB: Plaque formation by virulent Shigella flexneri. Infect Immun 1985, 48(1):124-129.

27. Hapfelmeier S, Ehrbar K, Stecher B, Barthel M, Kremer M, Hardt WD: Role of the Salmonella pathogenicity island 1 effector proteins SipA, SopB, SopE, and SopE2 in Salmonella enterica subspecies 1 serovar Typhimurium colitis in streptomycin-pretreated mice. Infect Immun 2004, 72(2):795-809.

28. Cai X, Zhang J, Chen M, Wu Y, Wang X, Chen J, Shen X, Qu D, Jiang H: The effect of the potential PhoQ histidine kinase inhibitors on Shigella flexneri virulence. PLoS One 2011, 6(8):e23100.

29. Yu J: Inactivation of DsbA, but not DsbC and DsbD, affects the intracellular survival and virulence of Shigella flexneri. Infect Immun 1998, 66(8):3909-3917.

30. Murayama SY, Sakai T, Makino S, Kurata T, Sasakawa C, Yoshikawa M: The use of mice in the Sereny test as a virulence assay of shigellae and enteroinvasive Escherichia coli. Infect Immun 1986, 51(2):696-698.

31. Pupo GM, Lan R, Reeves PR: Multiple independent origins of Shigella clones of Escherichia coli and convergent evolution of many of their characteristics. Proc Natl Acad Sci USA 2000, 97(19):10567-10572.

32. Yang J, Nie $H$, Chen L, Zhang $X$, Yang F, Xu X, Zhu Y, Yu J, Jin Q: Revisiting the molecular evolutionary history of Shigella spp. J Mol Evol 2007, 64(1):71-79.

33. Lan R, Reeves PR: Escherichia coli in disguise: molecular origins of Shigella. Microbes Infect 2002, 4(11):1125-1132.

34. Zurawski DV, Mumy KL, Faherty CS, McCormick BA, Maurelli AT: Shigella flexneri type III secretion system effectors OspB and OspF target the nucleus to downregulate the host inflammatory response via interactions with retinoblastoma protein. Mol Microbiol 2009, 71(2):350-368
35. Blocker A, Gounon P, Larquet E, Niebuhr K, Cabiaux V, Parsot C, Sansonetti $P$ : The tripartite type III secreton of Shigella flexneri inserts IpaB and IpaC into host membranes. J Cell Biol 1999, 147(3):683-693.

36. Buysse JM, Stover CK, Oaks EV, Venkatesan M, Kopecko DJ: Molecular cloning of invasion plasmid antigen (ipa) genes from Shigella flexneri: analysis of ipa gene products and genetic mapping. J Bacterio/ 1987 169(6):2561-2569.

37. Menard R, Sansonetti P, Parsot C: The secretion of the Shigella flexneri Ipa invasins is activated by epithelial cells and controlled by IpaB and IpaD. EMBO J 1994, 13(22):5293-5302

38. Menard R, Sansonetti PJ, Parsot C: Nonpolar mutagenesis of the ipa genes defines IpaB, IpaC, and IpaD as effectors of Shigella flexneri entry into epithelial cells. J Bacteriol 1993, 175(18):5899-5906.

39. Gaudio PA, Sethabutr O, Echeverria P, Hoge CW: Utility of a polymerase chain reaction diagnostic system in a study of the epidemiology of shigellosis among dysentery patients, family contacts, and well controls living in a shigellosis-endemic area. J Infect Dis 1997, 176(4):1013-1018.

40. Al-Hasani K, Henderson IR, Sakellaris H, Rajakumar K, Grant T, Nataro JP, Robins-Browne R, Adler B: The sigA gene which is borne on the she pathogenicity island of Shigella flexneri $2 a$ encodes an exported cytopathic protease involved in intestinal fluid accumulation. Infect Immun 2000, 68(5):2457-2463.

41. Navarro-Garcia F, Gutierrez-Jimenez J, Garcia-Tovar C, Castro LA, SalazarGonzalez H, Cordova V: Pic, an autotransporter protein secreted by different pathogens in the Enterobacteriaceae family, is a potent mucus secretagogue. Infect Immun 2010, 78(10):4101-4109.

42. Harrington SM, Sheikh J, Henderson IR, Ruiz-Perez F, Cohen PS, Nataro JP: The Pic protease of enteroaggregative Escherichia coli promotes intestinal colonization and growth in the presence of mucin. Infect Immun 2009, 77(6):2465-2473.

43. Ruiz-Perez F, Wahid R, Faherty CS, Kolappaswamy K, Rodriguez L, Santiago A, Murphy E, Cross A, Sztein MB, Nataro JP: Serine protease autotransporters from Shigella flexneri and pathogenic Escherichia coli target a broad range of leukocyte glycoproteins. Proc Natl Acad Sci USA 2011, 108(31):12881-12886.

44. Vidal JE, Navarro-Garcia F: EspC translocation into epithelial cells by enteropathogenic Escherichia coli requires a concerted participation of type V and III secretion systems. Cell Microbiol 2008, 10(10):1975-1986.

45. Greco R, De Martino L, Donnarumma G, Conte MP, Seganti L, Valenti P. Invasion of cultured human cells by Streptococcus pyogenes. Res Microbiol 1995, 146(7):551-560.

46. Prasad KN, Dhole TN, Ayyagari A: Adherence, invasion and cytotoxin assay of Campylobacter jejuni in HeLa and HEp-2 cells. J Diarrhoeal Dis Res 1996, 14(4):255-259.

47. Baumler AJ, Tsolis RM, Heffron F: Contribution of fimbrial operons to attachment to and invasion of epithelial cell lines by Salmonella typhimurium. Infect Immun 1996, 64(5):1862-1865.

doi:10.1186/1471-2180-13-31

Cite this article as: Zhang et al:: Deletion of pic results in decreased virulence for a clinical isolate of Shigella flexneri 2a from China. BMC Microbiology 2013 13:31.

\section{Submit your next manuscript to BioMed Central and take full advantage of:}

- Convenient online submission

- Thorough peer review

- No space constraints or color figure charges

- Immediate publication on acceptance

- Inclusion in PubMed, CAS, Scopus and Google Scholar

- Research which is freely available for redistribution 